I thank Messrs Paul Abrams, R C L Feneley, J C Gingell, J B M Roberts, and P $\mathrm{J} B$ Smith for permission to study their patients and for their help in preparing this paper.

1 Wallace DM, Harris DL. Delay in treating bladder tumours. Lancet 1965;ii:332-4.

2 Miller A, Mitchell JP, Brown NJ. The Bristol bladder tumour registry. Br 7 Urol 1969;41 (suppl): 1-64.

3 Mommsen S, Aagaard J, Sell A. Presenting symptoms, treatment delay and survival in bladder cancer. Scand J Urol Nephrol 1983;17:163-7.

(Accepted 9 March 1988)

Bristol Royal Infirmary and Southmead Hospital, Bristol

M J STOWER, DM, FRCS, senior registrar

Correspondence to: York District Hospital, York YO3 7HE.

\section{Response to D-Trp-6-luteinising hormone releasing hormone (Decapeptyl) microcapsules in advanced ovarian cancer}

D-Trp-6-luteinising hormone releasing hormone and other gonadotrophin releasing hormone agonists are proving useful in treating benign and malignant disease. ${ }^{12}$ We describe 39 patients with advanced ovarian cancer who were treated monthly with a long acting depot preparation of D-Trp-6-luteinising hormone releasing hormone.

\section{Patients, methods, and results}

Approval of the local ethical committee was obtained, and all patients gave informed consent. There were no specific exclusion criteria. All patients had a clinical examination with a full range of haematological and biochemical tests including assays of carcinoembryonic antigen, luteinising hormone, follicule stimulating hormone, prolactin, and $17 \beta$-oestradiol, and radiological investigations. These tests were repeated at follow up. Standard criteria of the International Union Against Cancer were used to assess clinical response.

All 39 patients (mean age 61 (range 42-79)) had a poor prognosis (International Federation of Gynaecology and Obstetrics grade III (31 patients) or IV (eight) disease) and a poor performance state $(40 \%$ on the Karnofksy performance index). The main sites of disease were pelvic or abdominal tumour (31), lymph nodes (five), metastases or effusion in the lung (five), liver metastases (eight), and ascites (12). Previous treatment comprised radiotherapy (29), chemotherapy with cisplatin or an analogue (35), and other chemotherapy (two); two had not had chemotherapy. The table shows the hormonal response to treatment. The mean oestrogen concentration was $<70 \mathrm{pmol} / \mathrm{l}$ before treatment and did not change significantly, but the concentration of gonadotrophins was significantly reduced at one month and subsequently throughout treatment $(p<0.001)$. Fifteen patients developed intestinal obstruction within the first eight weeks of treatment and continued to deteriorate. Six had severe intestinal obstruction at the start

Mean (SEM) hormonal response to treatment

\begin{tabular}{lccc}
\hline & $\begin{array}{c}\text { Follicle stimulating } \\
\text { hormone (U/l) }\end{array}$ & $\begin{array}{c}\text { Luteinising hormone } \\
(\mathrm{U} / \mathrm{l})\end{array}$ & $\begin{array}{c}17 \beta \text {-Oestradiol } \\
(\mathrm{pmol} / \mathrm{l})\end{array}$ \\
\hline Before treatment & $33 \cdot 0(0 \cdot 8)$ & $29 \cdot 7(0 \cdot 8)$ & $<70$ \\
After: & & & \\
1 Month & $3 \cdot 6(0 \cdot 1)$ & $4 \cdot 2(0 \cdot 3)$ & $<70$ \\
3 Months & $3 \cdot 2(0 \cdot 1)$ & $2 \cdot 7(0 \cdot 1)$ & $<70$ \\
6 Months & $3 \cdot 3(0 \cdot 2)$ & $2 \cdot 8(0 \cdot 2)$ & $<70$ \\
12 Months & $3 \cdot 4(0 \cdot 4)$ & $3 \cdot 5(0 \cdot 1)$ & $<70$ \\
\hline
\end{tabular}

of treatment, of whom one responded dramatically to treatment: her intestinal function returned to normal at three months and remained normal at six months.

Six patients achieved partial remission (overall response rate $15 \%$ ). The longest remission ( $>18$ months) occurred in a patient with a large abdominal mass. Five patients remained stable during treatment; they received the drug from six to 12 months. In 28 patients the tumour progressed; 25 of these patients died within the first 16 weeks. Mean survival was significantly longer in the six patients who responded (10 months (range six to 18$)$ than in those who did not $(p<0.05$, unpaired $t$ test). Response did not correlate with histological subtype or grade of cancer, and the histological findings were not significantly different in patients who responded and those who did not. Those who responded were older, and the natural course of their cancer seemed to be slower as most of them had had their disease for several years before the start of the study.

The drug was free of side effects.

\section{Comment}

Recently, luteinising hormone (human chorionic gonadotrophin) receptors were identified in tissue from ovarian cancers, and experimental studies showed increased growth of cell lines of human ovarian cancers treated with commercial luteinising hormone (human chorionic gonadotrophin) from the urine of pregnant women. Gonadotrophins have also been implicated in ovarian carcinogenesis. ${ }^{3}$ High capacity binding sites for luteinising hormone releasing hormone have been identified in tissue from ovarian cancers. ${ }^{4}$ The physiological role of these receptors is not known, but they may be one mechanism by which agonists of luteinising hormone releasing hormone inhibit growth of tumours. The predominant mechanism of action, however, is probably through suppression of gonadotrophins.

In a study in which patients who had relapsed after treatment with melphalan were given combination chemotherapy (including cisplatin) the response rate was only $30 \% .^{5}$ When cisplatin has been used as first line treatment response rates are even lower. This is similar to our results, although our patients generally had a worse prognosis. D-Trp-6-luteinising hormone releasing hormone is safe and useful for treating advanced ovarian cancer and can be recommended for patients who have relapsed after chemotherapy and those who cannot tolerate chemotherapy.

D-Trp-6-luteinising hormone releasing hormone (Decapeptyl) microcapsules for injection were kindly supplied by Ipsen International, 75016 Paris, France.

1 Shaw RW, Fraser HM, Boyle $\mathrm{H}$. Intranasal treatment with luteinising hormone releasing hormone agonist in women with endometriosis. BrMed 7 1983;287:1667-9.

2 Parmar H, Phillips̈RH, Lightman SL, Edwards L, Allen L, Schally AV. Randomised controlled study of orchidectomy versus long-acting D-Trp-6-LHRH microcapsules in advanced prostatic carcinoma. Lancet 1985;ii:1201-5.

3 Scott JS. How to induce ovarian cancer and how not to. Br Med f 1984;289:781.

4 Emons G, Strum R, Brack C, Knuppen R, Oberheuser F. GnRH binding sites in human epithelial ovarian cancer. F Steroid Biochem 1987;28(suppl):62S.

5 Richman CM, Podczaski E, Weiser PA, Herbst AL. Hexamethylmelamine, cyclophosphamide, adriamycin, cis-platinum chemotherapy as initial and second-line treatment of advanced ovarian carcinoma. Oncology 1986;43:12-7.

(Accepted 18 fanuary 1988)

Charing Cross and Westminster Medical School, London W6 8RP

H PARMAR, MB, CHB, research fellow in oncology

G RUSTIN, MSC, MRCP, senior lecturer in medical oncology

$S$ L LIGHTMAN, PHD, FRCP, reader in medicine

Westminster Hospital, London SW1P 2AP

R H PHILLIPS, MRCP, FRCR, consultant in radiotherapy and oncology

I W HANHAM, MRCP, FRCR, consultant in radiotherapy and oncology

Tulane University School of Medicine, Veterans Administration Medical Centre, New Orleans, United States

A V SCHALLY, PHD, director of experimental medicine

Correspondence to: Dr H Parmar, Department of Oncology, Westminster Hospital, London SW 1P 2AP. 